\title{
AIR POLLUTION EXPOSURE AND TELOMERE LENGTH IN HIGHLY EXPOSED SUBJECTS IN BEIJING, CHINA: A REPEATED-MEASURE STUDY
}

\author{
Lifang Hou ${ }^{*}, \mathrm{a}$, Sheng Wang ${ }^{*}, \mathrm{~b}$, Chang Dou ${ }^{\mathrm{c}}$, Xiao Zhang ${ }^{\mathrm{a}}$, Yue Yu ${ }^{\mathrm{a}}$, Yinan Zheng ${ }^{\mathrm{d}}$, \\ Umakanth Avula ${ }^{a}$, Mirjam Hoxha ${ }^{\mathrm{e}}$, Anaité Díaz ${ }^{f}$, John McCracken ${ }^{g}$, Francesco Barretta ${ }^{\mathrm{e}}$, \\ Barbara Marinellie, Pier Alberto Bertazzi ${ }^{\mathrm{e}}$, Joel Schwartz ${ }^{\mathrm{g}}$, and Andrea A. Baccarellig \\ aDepartment of Preventive Medicine, Feinberg School of Medicine, Northwestern University, 680 \\ N. Lake Shore Drive, Chicago, Illinois, USA. \\ ${ }^{b}$ Department of Occupational and Environmental Health, Peking University Health Science \\ Center, No. 38 Xueyuan Road, Haidian District, Beijing, China. \\ 'Department of Safety Engineering, China Institute of Industrial Health, No. 45 Zengguang Road, \\ Haidian District, Beijing, China. \\ dThe graduate school, Northwestern University, 633 Clark Street, Evanston, Illinois, USA. \\ eDepartment of Occupational and Environmental Health, Università degli Studi di Milano, \\ Fondazione IRCCS Ca' Granda - Ospedale Maggiore Policlinico, Via S. Barnaba 8, Milan, Italy. \\ fCenter for Health Studies, Universidad del Valle de Guatemala, 11 calle 15-70 zona 15 VHIII, \\ Guatemala City, Guatemala. \\ gDepartment of Environmental Health, Harvard School of Public Health, 665 Huntington Ave., \\ Boston, Massachusetts, USA.
}

\section{Abstract}

Background-Ambient particular matter (PM) exposure has been associated with short- and long-term effects on cardiovascular disease (CVD). Telomere length (TL) is a biomarker of CVD risk that is modified by inflammation and oxidative stress, two key pathways for PM effects. Whether PM exposure modifies TL is largely unexplored.

Objectives-To investigate effects of PM on blood TL in a highly-exposed population.

Methods-We measured blood TL in 120 blood samples from truck drivers and 120 blood samples from office workers in Beijing, China. We measured personal $\mathrm{PM}_{2.5}$ and Elemental Carbon (EC, a tracer of traffic particles) using light-weight monitors. Ambient $\mathrm{PM}_{10}$ was obtained from local monitoring stations. We used covariate-adjusted regression models to estimate percent changes in TL per an interquartile-range increase in exposure.

Results-Covariate-adjusted TL was higher in drivers (mean $=0.87,95 \% \mathrm{CI}: 0.74 ; 1.03$ ) than in office workers (mean $=0.79,95 \% \mathrm{CI}: 0.67 ; 0.93 ; \mathrm{p}=0.001$ ). In all participants combined, TL increased in association with personal $\mathrm{PM}_{2.5}(+5.2 \%, 95 \%$ CI: $1.5 ; 9.1 ; \mathrm{p}=0.007)$, personal EC $(+4.9 \%, 95 \%$ CI: $1.2 ; 8.8 ; \mathrm{p}=0.01)$, and ambient $\mathrm{PM}_{10}(+7.7 \%, 95 \% \mathrm{CI}: 3.7 ; 11.9 ; \mathrm{p}<0.001)$ on

*Corresponding authors: Lifang Hou, MD, PhD Department of Preventive Medicine Feinberg School of Medicine, Northwestern University 680 N Lake Shore Drive, Chicago, IL 60611 Phone: (312) 503-4798; Fax: (312) 908-9588 1-hou@ @orthwestern.edu Sheng Wang, MD, MPH Professor and Deputy Director Department of Occupational and Environmental Health Peking University Health Science Center Beijing, 100083, China Phone: 86 10-82801533; Fax: 86 10-82801533 shengw@ bjmu.edu.cn. 
examination days. In contrast, average ambient $\mathrm{PM}_{10}$ over the 14 days before the examinations was significantly associated with shorter TL $(-9.9 \%, 95 \% \mathrm{CI}:-17.6 ;-1.5 ; \mathrm{p}=0.02)$.

Conclusions-Short-term exposure to ambient PM is associated with increased blood TL, consistent with TL roles during acute inflammatory responses. Longer exposures may shorten TL as expected after prolonged pro-oxidant exposures. The observed TL alterations may participate in the biological pathways of short- and long-term PM effects.

\section{Keywords}

Particulate Matter; Personal Monitoring; Telomere length; Traffic pollution; China

\section{Introduction}

Epidemiological studies have consistently linked both short- and long-term exposure to ambient particulate matter (PM) to increased morbidity and mortality from cardiorespiratory disease (Brook et al. 2010; Chen et al. 2008; Dockery et al. 1993; Hassing et al. 2009; Ling and van Eeden 2009; Turner et al. 2011; Weinmayr et al. 2010). Increased oxidative stress and inflammation are two major mechanisms involved in mediating PM effects on human health (Chuang et al. 2007; Schwartz 2001; Seaton et al. 1995). Telomeres are composed of repeated TTAGGG segments of DNA located at the ends of chromosomes. These repeated sequences prevent degradation of DNA by exonucleases, unwanted recombination of chromosomes, and loss of genes by DNA replication (von Zglinicki 2002). The telomeric DNA regions at the ends of chromosomes appear to be particularly sensitive to reactive oxygen species (ROS) damage (Monaghan 2010). Telomere length (TL) decreases with age, and individuals with shorter telomeres in peripheral blood leukocytes (PBLs) show comparatively higher long-term risk of cardiovascular and respiratory disease (Cawthon et al. 2003; Epel et al. 2009; Fitzpatrick et al. 2007; Houben et al. 2009; Starr et al. 2008).

Several experiments have also shown that during acute inflammation, TL undergoes a transient increase (Weng et al. 1997). For inflammatory cells, the capacity for extensive cell division and clonal expansion is crucial to generate an effective response (Hodes et al. 2002). Cells with shortened telomeres lose their ability to divide and become senescent or undergo apoptosis (Blackburn 2001). In contrast, longer telomeres guarantee cell capacity for rapid proliferation (Hodes et al. 2002). These mechanisms have been demonstrated in lymphocytic subpopulations involved in acute inflammation, including in peripheral blood (Norrback et al. 1996; Weng et al. 1998). Short exposures to high levels of PM have been suggested to trigger acute events, such as acute myocardial infarction and asthma attacks (Brook et al. 2010; Weinmayr et al. 2010). Longer and protracted PM exposures have been shown to increase the risk of chronic diseases such as atherosclerosis, chronic obstructive pulmonary disease, and lung cancer (Brook et al. 2010; Chen et al. 2008; Ling and van Eeden 2009; Turner et al. 2011). Because of the direct biological links of oxidative stress and inflammation with both telomere lengthening and shortening, the time-dependent relations between PM exposure and TL hold substantial promises to identify novel mechanisms and biomarkers that may help to understand the acute and chronic health effects of air pollution.

Evidence on PM exposure and TL has begun to accumulate, with inconsistent results based on two recent studies showing shorter (McCracken et al. 2010) or longer (Dioni et al. 2011) TL in relation to PM exposure. A study on elderly individuals in Eastern Massachusetts showed that long-term (1-year) exposure to air particles from vehicular traffic was associated with reduced TL in PBLs (McCracken et al. 2010). However, a recent study of foundry workers with high exposure to metal-rich PM showed a rapid and significant 
increase in blood TL after three days of exposure to PM in the foundry (Dioni et al. 2011). Whether the inconsistency in these results is due to the duration or type of exposure is still undetermined.

Beijing is one of the most polluted cities in the world (World Bank, 2011). Traffic-derived air pollution is critical in Beijing due to very high population density, rapid increase in vehicular traffic, and limited emission control. Investigating individuals exposed to high levels of PM, such as those found in Beijing, may help to identify biomarker changes that might not be easily detectable in populations with lower exposure levels. In the present study, we aimed at investigating the time-dependent relationship of personal and ambient PM exposure measures with blood TL in truck drivers and indoor workers in Beijing, China.

\section{Methods}

\subsection{Study population and design}

For the 2008 Beijing Olympic Games, the Chinese authorities made concerted efforts to lower air pollution, including reducing the number of cars in the city and enforcing stringent emission standards for vehicles. The Beijing Truck Driver Air Pollution Study, conducted shortly before the Beijing Olympic Games (from June 15 to July 27, 2008), included 60 truck drivers and 60 indoor office workers. Because PM levels are highly variable on a dayto-day basis, we examined all subjects on two independent work days with 1-2 weeks intervals. All study participants had been on their current jobs for at least two years. The two groups were matched by sex, smoking and education, and partially (5-year intervals) by age. All study subjects lived in housing provided by their employers that were located nearby their offices or the truck-driver garages to avoid changes in blood pressure (BP), lung function, and heart rate related to the commuting. In-person interviews were conducted to collect information on demographics, lifestyle, and other exposures through a detailed questionnaire. Information on time-varying factors including tea, alcohol and smoking was obtained for past usual exposure, as well as on each examination day. Individual written informed consent was obtained from all participants prior to enrollment in the study. Institutional Review Board approval was obtained at all participating institutions.

\subsection{Personal exposure measurements}

We measured personal $\mathrm{PM}_{2.5}$ on both examination days using small-sized gravimetric samplers worn by the study subjects during the 8 hours of work. The sampler was carried in a belt pack with the inlet clipped near the breathing zone. Each sampler setup included an Apex pump (Casella Inc., Bedford, UK), a Triplex Sharp-Cut Cyclone (BGI Inc., Waltham, Massachusetts), and a 37-mm Teflon filter placed on top of a drain disc and inside a metal filter holder. The filters were kept under atmosphere-controlled conditions before and after sampling and were weighed with a microbalance (Mettler-Toledo Inc., Columbus, Ohio, USA). A time-weighted average of $\mathrm{PM}_{2.5}$ concentration was recorded by dividing the change in filter weight before and after sampling by the volume of air sampled. We found high reproducibility of $\mathrm{PM}_{2.5}$ measures $(\mathrm{r}=0.944)$ in replicate measures on a subset of 24 subjects who wore two monitors at the same time (Supplementary Figure 1). The blackness of the same filters used to measure $\mathrm{PM}_{2.5}$ was assessed using an EEL Model M43D Smokestain Reflectometer, applying the standard black-smoke index calculations of the absorption coefficients based on reflectance (ISO 1993). We assumed a factor of 1.0 for converting the absorption coefficient to EC mass (Janssen et al. 2001; Kinney et al. 2000), which was then divided by the sampled air volume to calculate average EC exposure concentration (ISO 1993). EC is a combustion by-product contained in PM that has been used as a surrogate measure for PM from gasoline- and especially diesel-powered motor vehicles (Kinney et al. 2000). 


\subsection{Ambient $\mathrm{PM}_{10}$ data}

Ambient $\mathrm{PM}_{10}$ data during the study period were obtained from the Beijing Municipal Environmental Bureau (http://www.bjepb.gov.cn/air2008/Air.aspx). We used daily averages of $\mathrm{PM}_{10}$ computed from data obtained from 27 monitoring stations to estimate the average $\mathrm{PM}_{10}$ level in Beijing. The monitoring stations are distributed across the area to represent Beijing city. Whereas personal $\mathrm{PM}_{2.5}$ and $\mathrm{EC}$ were measured only during work hours on examination days, ambient $\mathrm{PM}_{10}$ data are collected daily in Beijing. We used ambient $\mathrm{PM}_{10}$ data to reconstruct average exposures in Beijing on the days of the examination, as well as on the days leading to the examination days, thus allowing for testing effects on TL from longer time-windows of exposures than those captured by the personal monitors. We used multiple averaging time windows, which included the examination day (24 hour average), 1day mean ( 24 hour average of the day before the examinations), as well as averages of the 24 hour means of 1-2 days, 1-5 days, 1-7 days, 1-10 days and 1-14 days before the examinations. We obtained daily outdoor temperature data for Beijing city from the National Oceanic and Atmospheric Administration online database (NOAA).

\subsection{Blood collection, processing, and DNA extraction}

We collected $12 \mathrm{ml}$ blood at the end of each examination day from each participant. Buffy coat was separated within 2 hours and stored at $-80^{\circ} \mathrm{C}$ until DNA extraction. DNA was extracted using the Wizard Genomic DNA purification kit (Promega, Madison, WI) following the manufacturer's instructions. Purified DNA was resuspended on the kit hydration solution, quantified and stored at $-20^{\circ} \mathrm{C}$ until analysis.

\subsection{Telomere length $(T L)$ measurement}

We measured blood TL using the real-time quantitative PCR method developed by Cawthon (Cawthon 2002) with minor adaptations (Hoxha et al. 2009). This method measures the relative TL in genomic DNA by determining the ratio of telomere repeat copy number (T) to single copy gene (S) copy number (T/S ratio) in experimental samples relative to a reference sample. The T (telomere) and S (human beta-globin) PCR mix, and the thermal cycling profile for both amplicons were previously described (Hoxha et al. 2009). We used pooled control DNA samples from 20 randomly-selected indoor workers from this same study to create a fresh standard curve, ranging from $8 \mathrm{ng} / \mu \mathrm{l}$ to $0.25 \mathrm{ng} / \mu \mathrm{l}$, in every T and S PCR runs. All samples contained E. Coli DNA heated at $96^{\circ} \mathrm{C} \times 10$ minutes and cooled at room temperature. $15 \mathrm{ng}$ of DNA samples was added to each reaction (final volume $20 \mu \mathrm{l}$ ). All PCRs were performed in triplicate on a DNA Engine Thermal Cycler Chromo4 (Bio-Rad, Hercules, California, USA). DNA samples of truck drivers and office workers were interspersed across PCR plates to limit any potential plate effect bias. The intra-assay coefficient of variation $(\mathrm{CV})$ for the T/S ratio in the present study was $8.1 \%$. The RT-PCR reactions mean efficiency for telomere and $h b g$ reactions were $99.5 \%$ and $97.5 \%$, respectively.

\subsection{Statistical analysis}

Standard descriptive statistics were used to present the characteristics of truck drivers and office workers. TL was log-transformed to approximate a normal distribution. For variables that did not vary between the two examinations, such as age, sex, and usual smoking habits, differences in participant characteristics between the two groups were tested using Student's t-tests and chi-squares. For variables that varied between the two examinations, such as tea consumption or number of cigarettes smoked on each examination day, we evaluated differences between the two groups using mixed-effect regression models (PROC MIXED in SAS 9.2, SAS Institute Inc., Cary, NC). Similarly, we used mixed-effect regression models to test the differences between groups and estimate group-specific means and $95 \%$ 
Confidence Intervals (CIs). We fitted unadjusted mixed-effect models as well as models adjusted for variables either not matched or not completely matched by design between the two groups, i.e. age, BMI (continuous), cigarettes smoked during examination time (continuous), day of the week (one indicator variable per day), usage of central heating (yes/ no), time used for commuting to work (continuous), temperature (continuous) and dew point values (continuous). The mixed-effect regression models were:

$$
y_{i j}=\beta_{0}+\beta_{1}(\text { Group })_{i j}+\beta_{2} X_{2 i j}+\ldots+\beta_{n} X_{n i j}+\alpha_{1} X_{1 j}+\ldots+\alpha_{n} X_{n j}+\xi_{j}+e_{i j}
$$

where $\beta_{0}$ is the overall intercept; $\beta_{1}$ is the regression coefficient for the group; $\beta_{2} \ldots \beta_{n}$ are the regression coefficients for the time-dependent covariates included in multivariate models; $a_{1} \ldots a_{n}$ are the regression coefficients for the time-independent covariates included in multivariate models; $\xi_{j}$ is the random effect for the subject; $j$ represents the subject; $i$ identifies the workday and $e_{i j}$ is the residual error term.

We also used mixed-effect models adjusted for age, sex, BMI, cigarettes smoked during examination time, day of the week, usage of central heating, time used for commuting to work, temperature and dew point to evaluate the associations of personal $\mathrm{PM}_{2.5}$, personal $\mathrm{BC}$, and ambient $\mathrm{PM}_{10}$ variables with TL. Ambient $\mathrm{PM}_{10}$ was evaluated over different time windows ranging from the average levels on the examination day up to the average of 1-14 days prior to the examinations. In each of the models we fitted variables for temperature and dew points corresponding to the time window used for the particle variable. The mixedeffect models were:

$$
\left.y_{i j}=\beta_{0}+\beta_{1}(E x p)_{i j}+\beta_{2}(\text { Temp })_{i j}+\beta_{3} \text { (Dew point }\right)_{i j}+\beta_{4} X_{4 i j}+\ldots+\beta_{n} X_{n i j}+\alpha_{1} X_{1 j}+\ldots+\alpha_{n} X_{n j}+\xi_{j}+e_{i j}
$$

where $\beta_{0}$ is the overall intercept; $\beta_{1}$ is the regression coefficient for exposure variable (EC, $\mathrm{PM}_{2.5}$, or $\left.\mathrm{PM}_{10}\right) ; \beta_{2}$ and $\beta_{3}$ are the regression coefficients of the mean temperature and dew point, respectively, on the days of interest; $\beta_{3} \ldots \beta_{n}$ are the regression coefficients for the time-dependent covariates included in multivariate models; $a_{1} \ldots a_{n}$ are the regression coefficients for the time-independent covariates included in multivariate models; $\xi_{j}$ is the random effect for the subject; $j$ represents the subject; $i$ represents the examination day, and $e_{i j}$ is the residual error term. A two-sided alpha level of less than 0.05 was considered significant. All analyses were performed in SAS 9.2 (SAS Institute Inc., Cary, NC).

\section{Results}

\subsection{Characteristics of study subjects}

The characteristics of the 60 office workers and 60 truck drivers are shown in Table 1. Truck drivers were moderately, but significantly older than office workers. Truck drivers had higher BMI, reported more pack-years of smoking, smoked more cigarettes during the examination time, and included a higher proportion of usual alcohol drinkers, as well as of tea consumption.

\subsection{Personal $\mathrm{PM}_{2.5}$ and $\mathrm{EC}$, and ambient $\mathrm{PM}_{10}$ levels}

Table 2 shows the levels and distribution of personal time-weighted average exposure to $\mathrm{PM}_{2.5}$ and EC estimated during 8 work hours, as well as the mean levels of ambient $\mathrm{PM}_{10}$ on the examination day and over 14 days before the examination. Average personal $\mathrm{PM}_{2.5}$ was $126.8 \mu \mathrm{g} / \mathrm{m}^{3}$ for truck drivers and $94.6 \mu \mathrm{g} / \mathrm{m}^{3}$ for office workers $(\mathrm{p}<0.001)$. Average personal EC was $17.3 \mu \mathrm{g} / \mathrm{m}^{3}$ for truck drivers and $13.1 \mu \mathrm{g} / \mathrm{m}^{3}$ for office workers $(\mathrm{p}<0.001)$. 
As expected, the levels of ambient $\mathrm{PM}_{10}$ in the city of Beijing on the examination day as well as on the days before the examinations did not differ between truck drivers and office workers (Table 2).

\subsection{Telomere length in truck drivers and office workers}

In unadjusted analyses, no statistically significant differences in TL were found between the two groups (Table 3). In models adjusted by age, BMI, number of cigarettes smoked during examination time, day of the week, usage of central heating, time used for commuting to work, temperature and dew point, the TL mean was significantly higher in truck drivers $(0.87,95 \%$ CI: $0.74 ; 1.03)$ than in office workers $(0.79,95 \%$ CI: $0.67 ; 0.93 ; \mathrm{p}=0.002)$ (Table $3)$.

\subsection{Telomere length and levels of personal and ambient air particles exposure}

Table 4 shows the associations of TL with the levels of personal $\mathrm{PM}_{2.5}$ and $\mathrm{EC}$, and with the levels of ambient $\mathrm{PM}_{10}$. We expressed all results as percent changes in TL associated with an increase equal to the interquartile range (p75-p25) in the exposure variable. All results are adjusted by multiple covariates. In all subjects combined, personal $\mathrm{PM}_{2.5}$ exposure during the eight work hours on the examination days was associated with a $5.2 \%(95 \% \mathrm{CI}: 1.5 ; 9.1)$ increase in TL ( $\mathrm{p}=0.007$ ). The TL increase was equal to $6.5 \%$ (95\% CI: $1.9 ; 11.4 ; \mathrm{p}<0.001$ ) in office workers, whereas truck drivers showed a $2.1 \%$ non-significant change $(95 \% \mathrm{CI}$ : $-5.0 ; 9.8 ; \mathrm{p}=0.57)$. In all subjects combined, personal EC exposure during the eight work hours on the examination days was associated with a $4.9 \%(95 \% \mathrm{CI}: 1.2 ; 8.8)$ increase in TL $(\mathrm{p}=0.01)$. The TL increase was equal to $10.4 \%(95 \% \mathrm{CI}: 4.1 ; 17.1 ; \mathrm{p}=0.002)$ in office workers, whereas truck drivers showed a $0.4 \%$ non-significant change $(95 \% \mathrm{CI}:-4.9 ; 6.1$; $\mathrm{p}=0.88$ ).

By examining the levels of $\mathrm{PM}_{10}$ on and prior to the examinations days, we found that the 24-hour average of ambient levels of $\mathrm{PM}_{10}$ on the examination day was associated with increased TL in all subjects combined $(7.7 \%, 95 \%$ CI: $3.7 ; 11.9, \mathrm{p}<0.001)$, as well as in office workers $(8.6 \%, 95 \%$ CI: $3.2 ; 14.3, \mathrm{p}=0.003)$ and truck drivers $(8.0 \%, 95 \% \mathrm{CI}: 1.7$; $14.6, \mathrm{p}=0.02$ ), respectively. We also found the average $\mathrm{PM}_{10}$ over 2 days before the examinations associated with increased TL in all subjects combined $(8.1 \%, 95 \% \mathrm{CI}: 3.1$; 13.3, $\mathrm{p}=0.002)$, as well as in office workers $(10.1 \%, 95 \% \mathrm{CI}: 3.8 ; 16.8, \mathrm{p}=0.002)$ and marginally in truck drivers $(7.8 \%, 95 \% \mathrm{CI}:-0.2 ; 16.3, \mathrm{p}=0.06)$. However, the exposurerelated increase in TL appeared to decrease in association with longer (up to 10 days) exposure averaging times.

When TL was correlated with $\mathrm{PM}_{10}$ levels averaged over the 14 days before the day of the examination, we found a negative association equal to a $-9.9 \%$ change $(95 \% \mathrm{CI}:-17.6 ;-1.5$, $\mathrm{p}=0.02$ ) in all subjects combined (Table 4). The association was weaker in office workers $(-3.2 \%, 95 \%$ CI: $-14.9 ; 10.1, \mathrm{p}=0.62)$, and stronger and statistically significant in truck drivers alone $(-13.4 \%, 95 \% \mathrm{CI}:-24.2 ;-1.1, \mathrm{p}=0.04)$.

In this study population, we have previously examined the effects of ambient and personal $\mathrm{PM}$ exposure on $\mathrm{BP}$, finding a delayed effect of ambient $\mathrm{PM}_{10}$ on $\mathrm{BP}$ (Baccarelli et al. 2011). We examined the correlations of TL with BP and other risk factors, such as age and BMI. We observed an inverse association of TL with systolic BP $(\mathrm{p}=0.007)$ and diastolic BP $(\mathrm{p}<0.001)$, but not with other risk factors (Supplementary Table 1). In addition, we observed that men had shorter TL than women in this study population ( $\log \mathrm{TL}=0.153$ for men, and $\log \mathrm{TL}=0.237$ for women, $\mathrm{p}=0.016$ ). We further examined interactions between PM and sex on TL by adding an interaction term in the model. Statistical significance for interaction was assessed by the likelihood-ratio test comparing the models with and without the interaction 
term (Hosmer and Lemeshow 2000). We did not observe significant interaction between PM and sex on TL (Supplementary Table 2).

\section{DISCUSSION}

In the present investigation, we showed that levels of personal $\mathrm{PM}_{2.5}$ and $\mathrm{EC}$ during work hours on the examination days, as well as of ambient $\mathrm{PM}_{10}$ on or 1-2 days prior to the examinations were associated with increased TL. We observed no statistically significant associations of TL with ambient $\mathrm{PM}_{10}$ levels averaged over 1-5 days or 1-10 days before the examinations. However, we found a significant negative association of TL with the average of $\mathrm{PM}_{10}$ levels over 1-14 days prior to the examinations. In addition, truck drivers had longer TL than office workers in covariate-adjusted analyses.

Associations of ambient air pollution - both short-term peaks and long-term exposures with health outcomes, including cardiovascular and respiratory disease, have been consistently reported in a number of epidemiological studies. Inflammation and oxidative stress have been suggested as central mediators in the hypothesized biological mechanisms (Brook et al. 2010; Chuang et al. 2007; Schwartz 2001; Seaton et al. 1995). There is also consistent evidence that particle exposure induces oxidative DNA damage, and human panel studies have linked guanine oxidation, in particular, with particle exposure (GonzalezFlecha 2004; Risom et al. 2005). Oxidative stress induced by PM may arise from direct contact with reactive oxygen species on the surface of particles that are inhaled in the lungs, soluble compounds such as transition metals or organic compounds that reach the bloodstream, or activation of inflammatory cells that can generate reactive oxygen species (Risom et al. 2005). Telomeres naturally shorten with increasing age, and such process can be accelerated by chronic inflammation and increased oxidative stress (Hou and Gawron 2010; Jennings et al. 2000; Schonland et al. 2003; Valdes et al. 2005; von Zglinicki 2002; $\mathrm{Wu}$ et al. 2003). Because of high guanine content in specific telomere sequences, telomeres are remarkably sensitive to damage by oxidative stress (Houben et al. 2008) and telomeric DNA is deficient in the repair of single-strand breaks induced by oxidative DNA damage (Honda et al. 2001; Meeker et al. 2004; von Zglinicki 2002). TL attrition due to inflammation and oxidative stress is counteracted by telomerase, an enzymatic activity that plays a key role in stabilizing telomeres by adding hexameric (TTAGGG) repeats to the telomeric ends of the chromosomes (Hug and Lingner 2006). Telomerase activity can be detected in certain somatic tissues, including blood leukocytes (Hodes et al. 2002; Ornish et al. 2008; Sampedro Camarena et al. 2007). Therefore, telomeric DNA in blood leukocytes is dynamic, and TL results from the balance between processes that shorten telomeres and telomerase-dependent elongation of telomeres (Smogorzewska and de Lange 2004; Teixeira et al. 2004).

To date, two studies have examined the effects of PM exposure and blood leukocyte TL (Dioni et al. 2011; McCracken et al. 2010). Similar to the results in the present study on personal exposures on the examination days and short-term averages of ambient $\mathrm{PM}_{10}$ (1-2 days or shorter), a recent investigation by Dioni et al. (Dioni et al. 2011) showed a rapid and significant increase in blood TL after three days of exposure among foundry workers with high levels of PM exposure. In contrast, in non-smokers from the Boston area Normative Aging Study, McCracken et al. showed shortened blood leukocyte TL in association with higher levels of long-term exposure to black carbon - a tracer of PM from vehicular traffic emissions equivalent to $\mathrm{EC}$ - estimated as average ambient levels in the year before the examination at the participants' residences (McCracken et al. 2010). In line with the study by McCracken et al., we also found that longer exposure to PM (14-day average of ambient $\mathrm{PM}_{10}$ ) is associated with decreased TL. Our findings, interpreted together with previous studies, indicate that short-term PM exposures might produce an acute increase in TL that 
could participate in sustaining the inflammatory mechanisms associated with acute PM health effects (Dioni et al. 2011). Longer exposures might cause telomere shortening, which, as suggested by longitudinal studies linking shorter PBL TL with increased long-term risk of cardiovascular and respiratory disease (Cawthon et al. 2003; Epel et al. 2009; Fitzpatrick et al. 2007; Houben et al. 2009; Starr et al. 2008), may contribute to or at least serve as a biological marker of PM-related chronic diseases.

In this study population, we previously reported a delayed effect of ambient $\mathrm{PM}_{10}$ on $\mathrm{BP}$ (Baccarelli et al. 2011). Our finding of an inverse association of TL with both systolic and diastolic BP is in line with previous studies, showing an inverse correlation between TL in blood and BP (Fitzpatrick et al. 2007; Jeanclos et al. 2000). Two other studies have shown that hypertension is associated with telomere shortening in Japanese (Nakashima et al. 2004) and Indian population (Bhupatiraju et al. 2012). It is possible that higher blood pressure may lead to shorter TL. Larger prospective studies are needed to understand the temporal relationships between air pollution, BP, and TL. Our observation that men have shorter TL than women is consistent with previous reports showing shorter TL in men than women (Jeanclos et al. 2000; Mayer et al. 2006). Okuda found there is no sex-related difference in $\mathrm{TL}$ at birth (Okuda et al. 2002). However, males had higher attrition rates, which may result in shorter TL in men compared with that in women (Mayer et al. 2006). Also the antioxidative capacity of estrogen may contribute to TL maintenance in women (Aviv 2002). However, the exact underlying mechanisms are still largely unknown.

We found longer TL in truck drivers compared to indoor workers after adjusting for potential confounders. Because our samples were collected right after work and truck drivers had higher exposure, we hypothesize that the observed longer TL in truck drivers is attributable to the acute increase in TL associated with short-term PM exposures. However, we cannot exclude that other unmeasured characteristics, that were different between the two groups may have also served a role in affecting TL, including lifestyle factors or other environmental exposures (Cassidy et al. 2010; Hou et al. 2012; Ornish et al. 2008). Further larger and longitudinal studies by including such factors will certainly help to determine the time- and exposure-dependent components of TL changes induced by PM exposure.

While our study population is not representative of populations globally, consistent internal validity and adjustment for the various lifestyle factors and demographic characteristics in this investigation allow for moderate generalizability. Our study has several strengths. Our investigation had the advantage of having both personal and ambient measures of air pollution. We conducted technical validation of personal $\mathrm{PM}_{2.5}$ measures that showed high reproducibility ( $\mathrm{r}=0.944)$ of our measurements. All participants were evaluated using standardized protocols for blood collection and storage. Blood DNA samples were randomized across plates to limit potential bias from plate effects and laboratory personnel were blinded to exposure groups and exposure levels of the samples. We also recognize several limitations to our study. In our investigation, we did not examine inflammatory markers that may play important roles in both TL shortening and PM-related diseases, thus limiting our ability of understanding how inflammation interacts with PM-related TL changes. Further studies are needed to examine cytokines, in particular, IL2, IL4, IL6, IL8, and TNFa that have been previously associated with PM exposure (Becker et al. 2005; Nurkiewicz et al. 2006; Nurkiewicz et al. 2011), and high-sensitivity C-reactive protein (hs$\mathrm{CRP}$ ) to clarify the role of inflammation in the relation of TL with PM exposure. Because of the relatively small sample size, we cannot exclude false negative findings, as well as chance findings. Some of the differences in the associations with the exposures between truck drivers and office workers might be due to the small sample sizes of the two groups. In addition to using personal $\mathrm{PM}_{2.5}$ and $\mathrm{EC}$ measures, we utilized stationary measures of ambient $\mathrm{PM}_{10}$, which are just a proxy of personal exposure. However, simulation studies 
have shown that the error introduced by using data from stationary monitors is highly unlikely to bias away from the null, and indicated that this exposure misclassification may lead to an underestimation of the health effects of air pollution (Zeger et al. 2000).

\title{
5. CONCLUSIONS
}

Overall, our investigation provides evidence that short-term exposure to air pollution may increase TL, whereas longer exposure may lead to shorter TL. Both the rapid TL increase and the progressive time-dependent decrease in TL are potentially related to inflammatory and oxidative processes underlying the effects of PM on human health. Our findings, if confirmed in additional investigations, would substantially further our understanding of invivo TL biology and provide valuable information for the design and timing of blood sample collections for future studies of environmental effects on TL.

\section{Supplementary Material}

Refer to Web version on PubMed Central for supplementary material.

\section{Acknowledgments}

This work was supported by funding from the NIEHS (ES00002 and R21ES020010), and the Harvard EPA Center (RD 83479801).

\author{
Abbreviations

$\begin{array}{ll}\text { BC } & \text { Black Carbon } \\ \text { BP } & \text { Blood Pressure } \\ \text { BTDAS } & \text { Beijing Truck Driver Air Pollution Study } \\ \text { CI } & \text { Confidence Interval } \\ \text { PM } & \text { Particulate Matter } \\ \text { PM }_{2.5} & \text { Particulate Matter } \_.5 \mu \mathrm{m} \\ \text { PM }_{10} & \text { Particulate Matter } \unlhd 10 \mathrm{~m} \\ \text { ROS } & \text { Reactive Oxygen Species } \\ \text { SD } & \text { Standard Deviation } \\ \text { TL } & \text { Telomere Length }\end{array}$

REFERENCES

Aviv A. Telomeres, sex, reactive oxygen species, and human cardiovascular aging. J Mol Med (Berl). 2002; 80:689-695. [PubMed: 12436345]

Baccarelli A, Barretta F, Dou C, Zhang X, McCracken JP, Diaz A, Bertazzi PA, Schwartz J, Wang S, Hou LF. Effects of particulate air pollution on blood pressure in a highly exposed population in Beijing, China: a repeated-measure study. Environ Health-Glob. 2011; 10

Bank W. World Development Indicators. 2011

Becker S, Mundandhara S, Devlin RB, Madden M. Regulation of cytokine production in human alveolar macrophages and airway epithelial cells in response to ambient air pollution particles: further mechanistic studies. Toxicol Appl Pharmacol. 2005; 207:269-275. [PubMed: 15993911]

Bhupatiraju C, Saini D, Patkar S, Deepak P, Das B, Padma T. Association of shorter telomere length with essential hypertension in Indian population. Am J Hum Biol. 2012 
Blackburn EH. Switching and signaling at the telomere. Cell. 2001; 106:661-673. [PubMed: 11572773]

Brook RD, Rajagopalan S, Pope CA 3rd, Brook JR, Bhatnagar A, Diez-Roux AV, Holguin F, Hong Y, Luepker RV, Mittleman MA, Peters A, Siscovick D, Smith SC Jr. Whitsel L, Kaufman JD. Particulate matter air pollution and cardiovascular disease: An update to the scientific statement from the American Heart Association. Circulation. 2010; 121:2331-2378. [PubMed: 20458016]

Cassidy A, De Vivo I, Liu Y, Han J, Prescott J, Hunter DJ, Rimm EB. Associations between diet, lifestyle factors, and telomere length in women. Am J Clin Nutr. 2010; 91:1273-1280. [PubMed: 20219960]

Cawthon RM. Telomere measurement by quantitative PCR. Nucleic Acids Res. 2002; 30:e47. [PubMed: 12000852]

Cawthon RM, Smith KR, O’Brien E, Sivatchenko A, Kerber RA. Association between telomere length in blood and mortality in people aged 60 years or older. Lancet. 2003; 361:393-395. [PubMed: 12573379]

Chen H, Goldberg MS, Villeneuve PJ. A systematic review of the relation between long-term exposure to ambient air pollution and chronic diseases. Rev Environ Health. 2008; 23:243-297. [PubMed: 19235364]

Chuang KJ, Chan CC, Su TC, Lee CT, Tang CS. The effect of urban air pollution on inflammation, oxidative stress, coagulation, and autonomic dysfunction in young adults. Am J Respir Crit Care Med. 2007; 176:370-376. [PubMed: 17463411]

Dioni L, Hoxha M, Nordio F, Bonzini M, Tarantini L, Albetti B, Savarese A, Schwartz J, Bertazzi PA, Apostoli P, Hou L, Baccarelli A. Effects of short-term exposure to inhalable particulate matter on telomere length, telomerase expression, and telomerase methylation in steel workers. Environ Health Perspect. 2011; 119:622-627. [PubMed: 21169126]

Dockery DW, Pope CA 3rd, Xu X, Spengler JD, Ware JH, Fay ME, Ferris BG Jr. Speizer FE. An association between air pollution and mortality in six U. S. cities. N Engl J Med. 1993; 329:17531759. [PubMed: 8179653]

Epel ES, Merkin SS, Cawthon R, Blackburn EH, Adler NE, Pletcher MJ, Seeman TE. The rate of leukocyte telomere shortening predicts mortality from cardiovascular disease in elderly men. Aging (Albany NY). 2009; 1:81-88. [PubMed: 20195384]

Fitzpatrick AL, Kronmal RA, Gardner JP, Psaty BM, Jenny NS, Tracy RP, Walston J, Kimura M, Aviv A. Leukocyte telomere length and cardiovascular disease in the cardiovascular health study. Am J Epidemiol. 2007; 165:14-21. [PubMed: 17043079]

Gonzalez-Flecha B. Oxidant mechanisms in response to ambient air particles. Mol Aspects Med. 2004; 25:169-182. [PubMed: 15051325]

Hassing HC, Twickler TB, Kastelein JJ, Cramer MJ, Cassee FR. Air pollution as noxious environmental factor in the development of cardiovascular disease. Neth J Med. 2009; 67:116121. [PubMed: 19581654]

Hodes RJ, Hathcock KS, Weng NP. Telomeres in T and B cells. Nat Rev Immunol. 2002; 2:699-706. [PubMed: 12209138]

Honda S, Hjelmeland LM, Handa JT. Oxidative stress--induced single-strand breaks in chromosomal telomeres of human retinal pigment epithelial cells in vitro. Invest Ophthalmol Vis Sci. 2001; 42:2139-2144. [PubMed: 11481283]

Hosmer, DW.; Lemeshow, S. Applied logistic regression. Wiley; New York: 2000. Introduction to the logistic regression model: testing for the significance of the coefficients.

Hou L, Gawron AJ. Telomere Length and Cancer Risk: Cause or Consequence, Long or Short? American Association for Cancer Research (AACR) Education Book. 2010

Hou L, Zhang X, Gawron AJ, Liu J. Surrogate tissue telomere length and cancer risk: Shorter or Longer? Cancer Lett. 2012

Houben JM, Mercken EM, Ketelslegers HB, Bast A, Wouters EF, Hageman GJ, Schols AM. Telomere shortening in chronic obstructive pulmonary disease. Respir Med. 2009; 103:230-236. [PubMed: 18945604]

Houben JM, Moonen HJ, van Schooten FJ, Hageman GJ. Telomere length assessment: biomarker of chronic oxidative stress? Free Radic Biol Med. 2008; 44:235-246. [PubMed: 18021748] 
Hoxha M, Dioni L, Bonzini M, Pesatori AC, Fustinoni S, Cavallo D, Carugno M, Albetti B, Marinelli B, Schwartz J, Bertazzi PA, Baccarelli A. Association between leukocyte telomere shortening and exposure to traffic pollution: a cross-sectional study on traffic officers and indoor office workers. Environ Health. 2009; 8:41. [PubMed: 19772576]

Hug N, Lingner J. Telomere length homeostasis. Chromosoma. 2006; 115:413-425. [PubMed: 16741708]

ISO. ISO 9835, Ambient air - Determination of a black smoke index. International Organization for Standardization; Geneva: 1993.

Janssen NA, van Vliet PH, Aarts F, Harssema H, Brunekree B. Assessment of exposure to traffic related air pollution of children attending schools near motorways. Atmospheric Environment. 2001; 35:3875-3884.

Jeanclos E, Schork NJ, Kyvik KO, Kimura M, Skurnick JH, Aviv A. Telomere length inversely correlates with pulse pressure and is highly familial. Hypertension. 2000; 36:195-200. [PubMed: 10948077]

Jennings BJ, Ozanne SE, Hales CN. Nutrition, oxidative damage, telomere shortening, and cellular senescence: individual or connected agents of aging? Mol Genet Metab. 2000; 71:32-42. [PubMed: 11001793]

Kinney PL, Aggarwal M, Northridge ME, Janssen NA, Shepard P. Airborne concentrations of PM(2.5) and diesel exhaust particles on Harlem sidewalks: a community-based pilot study. Environ Health Perspect. 2000; 108:213-218. [PubMed: 10706526]

Ling SH, van Eeden SF. Particulate matter air pollution exposure: role in the development and exacerbation of chronic obstructive pulmonary disease. Int J Chron Obstruct Pulmon Dis. 2009; 4:233-243. [PubMed: 19554194]

Mayer S, Bruderlein S, Perner S, Waibel I, Holdenried A, Ciloglu N, Hasel C, Mattfeldt T, Nielsen $\mathrm{KV}$, Moller P. Sex-specific telomere length profiles and age-dependent erosion dynamics of individual chromosome arms in humans. Cytogenet Genome Res. 2006; 112:194-201. [PubMed: 16484772]

McCracken J, Baccarelli A, Hoxha M, Dioni L, Melly S, Coull B, Suh H, Vokonas P, Schwartz J. Annual ambient black carbon associated with shorter telomeres in elderly men: Veterans Affairs Normative Aging Study. Environ Health Perspect. 2010; 118:1564-1570. [PubMed: 21465749]

Meeker AK, Hicks JL, Iacobuzio-Donahue CA, Montgomery EA, Westra WH, Chan TY, Ronnett BM, De Marzo AM. Telomere length abnormalities occur early in the initiation of epithelial carcinogenesis. Clin Cancer Res. 2004; 10:3317-3326. [PubMed: 15161685]

Monaghan P. Telomeres and life histories: the long and the short of it. Ann N Y Acad Sci. 2010; 1206:130-142. [PubMed: 20860686]

Nakashima H, Ozono R, Suyama C, Sueda T, Kambe M, Oshima T. Telomere attrition in white blood cell correlating with cardiovascular damage. Hypertens Res. 2004; 27:319-325. [PubMed: 15198478]

NOAA. NNDC Climate Data Online. US Department of Commerce; 2011.

Norrback KF, Dahlenborg K, Carlsson R, Roos G. Telomerase activation in normal B lymphocytes and non-Hodgkin's lymphomas. Blood. 1996; 88:222-229. [PubMed: 8704177]

Nurkiewicz TR, Porter DW, Barger M, Millecchia L, Rao KM, Marvar PJ, Hubbs AF, Castranova V, Boegehold MA. Systemic microvascular dysfunction and inflammation after pulmonary particulate matter exposure. Environ Health Perspect. 2006; 114:412-419. [PubMed: 16507465]

Nurkiewicz TR, Porter DW, Hubbs AF, Stone S, Moseley AM, Cumpston JL, Goodwill AG, Frisbee SJ, Perrotta PL, Brock RW, Frisbee JC, Boegehold MA, Frazer DG, Chen BT, Castranova V. Pulmonary particulate matter and systemic microvascular dysfunction. Res Rep Health Eff Inst. 2011:3-48. [PubMed: 22329339]

Okuda K, Bardeguez A, Gardner JP, Rodriguez P, Ganesh V, Kimura M, Skurnick J, Awad G, Aviv A. Telomere length in the newborn. Pediatr Res. 2002; 52:377-381. [PubMed: 12193671]

Ornish D, Lin J, Daubenmier J, Weidner G, Epel E, Kemp C, Magbanua MJ, Marlin R, Yglecias L, Carroll PR, Blackburn EH. Increased telomerase activity and comprehensive lifestyle changes: a pilot study. Lancet Oncol. 2008; 9:1048-1057. [PubMed: 18799354] 
Risom L, Moller P, Loft S. Oxidative stress-induced DNA damage by particulate air pollution. Mutat Res. 2005; 592:119-137. [PubMed: 16085126]

Sampedro Camarena F, Cano Serral G, Sampedro Santalo F. Telomerase and telomere dynamics in ageing and cancer: current status and future directions. Clin Transl Oncol. 2007; 9:145-154. [PubMed: 17403625]

Schonland SO, Lopez C, Widmann T, Zimmer J, Bryl E, Goronzy JJ, Weyand CM. Premature telomeric loss in rheumatoid arthritis is genetically determined and involves both myeloid and lymphoid cell lineages. Proc Natl Acad Sci U S A. 2003; 100:13471-13476. [PubMed: 14578453]

Schwartz J. Air pollution and blood markers of cardiovascular risk. Environ Health Perspect. 2001; 109(Suppl 3):405-409. [PubMed: 11427390]

Seaton A, MacNee W, Donaldson K, Godden D. Particulate air pollution and acute health effects. Lancet. 1995; 345:176-178. [PubMed: 7741860]

Smogorzewska A, de Lange T. Regulation of telomerase by telomeric proteins. Annu Rev Biochem. 2004; 73:177-208. [PubMed: 15189140]

Starr JM, Shiels PG, Harris SE, Pattie A, Pearce MS, Relton CL, Deary IJ. Oxidative stress, telomere length and biomarkers of physical aging in a cohort aged 79 years from the 1932 Scottish Mental Survey. Mech Ageing Dev. 2008; 129:745-751. [PubMed: 18977241]

Teixeira MT, Arneric M, Sperisen P, Lingner J. Telomere length homeostasis is achieved via a switch between telomerase-extendible and -nonextendible states. Cell. 2004; 117:323-335. [PubMed: 15109493]

Turner MC, Krewski D, Pope Iii CA, Chen Y, Gapstur SM, Thun MJ. Long-Term Ambient Fine Particulate Matter Air Pollution and Lung Cancer in a Large Cohort of Never Smokers. Am J Respir Crit Care Med. 2011

Valdes AM, Andrew T, Gardner JP, Kimura M, Oelsner E, Cherkas LF, Aviv A, Spector TD. Obesity, cigarette smoking, and telomere length in women. Lancet. 2005; 366:662-664. [PubMed: 16112303]

von Zglinicki T. Oxidative stress shortens telomeres. Trends Biochem Sci. 2002; 27:339-344. [PubMed: 12114022]

Weinmayr G, Romeo E, De Sario M, Weiland SK, Forastiere F. Short-term effects of PM10 and NO2 on respiratory health among children with asthma or asthma-like symptoms: a systematic review and meta-analysis. Environ Health Perspect. 2010; 118:449-457. [PubMed: 20064785]

Weng NP, Granger L, Hodes RJ. Telomere lengthening and telomerase activation during human B cell differentiation. Proc Natl Acad Sci U S A. 1997; 94:10827-10832. [PubMed: 9380719]

Weng NP, Hathcock KS, Hodes RJ. Regulation of telomere length and telomerase in T and B cells: a mechanism for maintaining replicative potential. Immunity. 1998; 9:151-157. [PubMed: 9729035]

World Bank. World Development Indicators. 2011. http://data.worldbank.org/data-catalog/worlddevelopment-indicators

Wu X, Amos CI, Zhu Y, Zhao H, Grossman BH, Shay JW, Luo S, Hong WK, Spitz MR. Telomere dysfunction: a potential cancer predisposition factor. J Natl Cancer Inst. 2003; 95:1211-1218. [PubMed: 12928346]

Zeger SL, Thomas D, Dominici F, Samet JM, Schwartz J, Dockery D, Cohen A. Exposure measurement error in time-series studies of air pollution: concepts and consequences. Environ Health Perspect. 2000; 108:419-426. [PubMed: 10811568] 
Table 1

Study subjects characteristics.

\begin{tabular}{|c|c|c|c|}
\hline & $\begin{array}{l}\text { Office Workers } \\
(n=60)\end{array}$ & $\begin{array}{c}\text { Truck Drivers } \\
(\mathbf{n}=60)\end{array}$ & p-value ${ }^{a}$ \\
\hline \multicolumn{4}{|l|}{ Sex, $n(\%)$} \\
\hline Male & $40(66.7)$ & $40(66.7)$ & \\
\hline Female & $20(33.3)$ & $20(33.3)$ & 1.00 \\
\hline \multicolumn{4}{|l|}{ Smoking, n (\%) } \\
\hline Never smoker & $35(58.4)$ & $34(56.7)$ & \\
\hline Former & $2(3.3)$ & $2(3.3)$ & \\
\hline Current & $23(38.3)$ & $24(40.0)$ & 1.00 \\
\hline Age [Years], mean (SD) & $30.27 \pm 7.96$ & $33.5 \pm 5.7$ & 0.004 \\
\hline BMI $\left[\mathrm{kg} / \mathrm{m}^{2}\right]$, mean $(\mathrm{SD})$ & $22.76 \pm 3.38$ & $24.3 \pm 3.2$ & 0.01 \\
\hline \multicolumn{4}{|c|}{ Tea consumption during the time of the examination, $n(\%)$} \\
\hline No & $109(90.83)$ & $86(71.7)$ & \\
\hline Yes & $11(9.17)$ & $34(28.3)$ & $0.003^{b}$ \\
\hline \multicolumn{4}{|l|}{ Usual alcohol drinking, n (\%) } \\
\hline No & $46(76.7)$ & $29(48.3)$ & \\
\hline Yes & $14(23.3)$ & $31(51.7)$ & 0.002 \\
\hline \multicolumn{4}{|c|}{ Centralized heating system in building, $n(\%)$} \\
\hline No & $108(90.0)$ & $88(73.3)$ & \\
\hline Yes & $12(10.0)$ & $32(26.7)$ & 0.03 \\
\hline \multicolumn{4}{|l|}{ Day of the week, $n(\%)$} \\
\hline Monday & $16(13.3)$ & $19(15.8)$ & \\
\hline Tuesday & $18(15.0)$ & $13(10.8)$ & \\
\hline Wednesday & $14(11.7)$ & $15(12.5)$ & \\
\hline Thursday & $15(12.5)$ & $20(16.7)$ & \\
\hline Friday & $17(14.2)$ & $19(15.8)$ & \\
\hline Saturday & $18(15.0)$ & $16(13.3)$ & \\
\hline Sunday & $22(18.3)$ & $18(15.0)$ & $0.88^{b}$ \\
\hline $\begin{array}{l}\text { Daily time spent in commute to } \\
\text { work [Minutes], mean (SD) }\end{array}$ & $6.3 \pm 8.0$ & $12.3 \pm 15.2$ & 0.02 \\
\hline $\begin{array}{l}\text { Cigarettes smoked on the } \\
\text { examination day [cigarettes/day], } \\
\text { mean (SD) }\end{array}$ & $2.6 \pm 5.2$ & $6.4 \pm 9.4$ & $<0.001^{b}$ \\
\hline $\begin{array}{l}\text { Average temperature on two } \\
\text { examination days, mean (SD) }\end{array}$ & $25.4 \pm 2.5$ & $25.3 \pm 2.5$ & $0.96^{b}$ \\
\hline $\begin{array}{l}\text { Average dew point on two } \\
\text { examination days, mean (SD) }\end{array}$ & $20.6 \pm 2.1$ & $20.6 \pm 2.1$ & $0.93^{b}$ \\
\hline $\begin{array}{l}\text { Systolic blood pressure [mmHg], } \\
\text { mean (SD) }\end{array}$ & $115.3 \pm 11.7$ & $116.3 \pm 13.3$ & 0.56 \\
\hline $\begin{array}{l}\text { Diastolic blood pressure [mmHg], } \\
\text { mean (SD) }\end{array}$ & $77.6 \pm 8.3$ & $80.2 \pm 9.7$ & 0.03 \\
\hline
\end{tabular}

${ }^{a}$ P-values were calculated using Student's t-test and Fisher's exact test for continuous and categorical variables, respectively, except for the variables indicated at the footnote $b$ below. 
${ }^{b}$ Cumulative of the two examination days. P-values were obtained from mixed-effects regression models. 
娄|

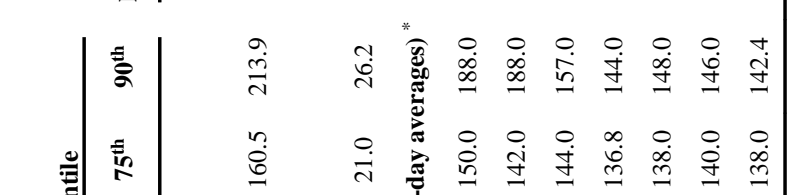

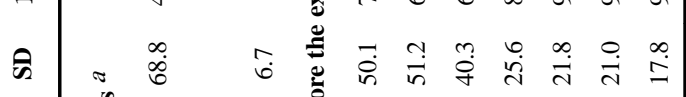
宽 。ิ

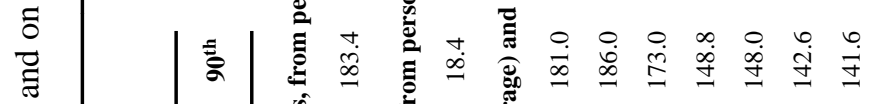




\section{Table 3}

Mean blood leukocyte telomere length (TL) in truck drivers and office workers.

\begin{tabular}{lccccccc}
\hline & \multicolumn{2}{c}{$\begin{array}{c}\text { Office Workers } \\
(\text { obs=120) }\end{array}$} & & \multicolumn{2}{c}{$\begin{array}{c}\text { Truck Drivers } \\
(\mathbf{o b s}=\mathbf{1 2 0})\end{array}$} & p-value \\
\cline { 2 - 3 } & Mean & $\mathbf{( 9 5 \%} \mathbf{~ C I})$ & & Mean & $\mathbf{( 9 5 \%} \mathbf{C I})$ & \\
\hline Unadjusted & 0.88 & $0.85 ; 0.91$ & & 0.91 & $0.88 ; 0.95$ & 0.16 \\
Adjusted ${ }^{a}$ & 0.79 & $0.67 ; 0.93$ & & 0.87 & $0.74 ; 1.03$ & 0.002 \\
\hline
\end{tabular}

${ }^{a}$ Adjusted for age, BMI, number of cigarettes smoked during examination time, day of the week, usage of central heating, time used for commuting to work, temperature and dew point values. 
